\title{
Thermal Studies of Polymeric Foams Used in Engineering
}

\author{
Natalia V.Romanova*1, Lenar N. Shafigullin ${ }^{2}$, Tamara M. Kokina ${ }^{3}$, IbrahimovAynar R. ${ }^{4}$, Gulnaz R. \\ Shafigullina ${ }^{5}$ \\ 1, 2, 3, 4, 5 Kazan Federal University, Naberezhnye Chelny Institute, \\ E-mail: romanova.nv@kamaz.rul, misharin_82@mail.ru², dtp777@mail.ru33, ibragimov.a.r@mail.ru4,$\underline{k r i t 8181 @ m a i l . r u^{5}}$
} Contact: 89375798597, 89053748947, 89272497023, 89274562211, 89625732572.

\section{Received: 21st October 2017 Accepted: 16th November 2017, Published: 31st December 2017}

\begin{abstract}
Polymeric foams, used in the production of aircraft, are consideredin the article. Thermogravimetric analysis and differential scanning calorimetry were used to conduct thermal studies of rigid polyimide foam materials. It was shown, that the process of thermal destruction of these foams hadthree stages of different intensity: the destruction of rigid segment with the formation of initial components and the emission of volatile elements; the activation of thermo-oxidative processes; the decomposition, accompanied by considerable heatrelease. Infrared spectroscopy was used to estimate the influence of the content of volatile components on the glass transition temperature of rigid polyimide foams. It was found, that the presence of volatile substances led to a decrease in the glass transition temperature of the foam materials.
\end{abstract}

Keywords: Foams, Rigid Polyimide Foams, IR Spectroscopy, Thermal Studies, Thermal Destruction.

\section{Introduction}

At present, various brands of elastic and rigid gasfilled materials are used in all branches of industry and construction [1-5]. The issue of development of new compositions of polymer foams, whichcan meet the requirements of lowering their prime costs, reducing toxicity in production, and also the possibility of their operation under different temperature conditions, becomes topical. The use of a large number of initialcomponents during production makes it possible to vary the properties of the resulting polymer foams [2, 4]. For example, the introduction of fillers is widely used for the production of materials with specified technological and operational properties, and for the reduction of their cost. In addition, filling leads to a certain decrease in the combustibility of polymers [6].

As the fillers of polymeric foam materials, traditional disperse and reinforcing fibrous fillers (RFF) can be used [7-8].

The mechanical properties of fibrous polymer composites are determined by reinforcing fibers and filaments (by their types and properties, size and location, that is, the structure of the reinforcing fibrous filler). Fibers, filaments, strings, rovings, slubbings, cables, fabrics, woven fabrics, knitted fabrics, nonwoven fabrics, paper and othermaterials are used as reinforcing fibrous fillers.

Using different types of RFF and technological methods of their location in the fiber composite, it is possible to optimize the positioning of reinforcing fibers and filaments in a finished composite or a product on its base, to achieve the most rational variant, wherethe majority of reinforcing fibers are located in the direction of the main acting mechanical stresses under operating conditions.

Glass-filled polymeric foams make it possible to manufacture large-sized elements with a multi-layer structure, composed of various combinations of solid and porous foam material and short glass fibers, formeeting various functional and aesthetic requirements in different fields of application. Glassfilled polymeric foams are widely used for the production of carcasses, heat-insulating screens in the automotive industry [3, 9-11].

Polymeric foams also find wide application in the production of aircraft. Polymethacrylimide foam materials are the most widely used in the production of laminated materials, which along with high thermal stability, low density and increased mechanical properties, are well combined with resins, that makes them suitable materials for aircraft construction.

It is known, that the main method of production the polymer foam materials is the foamingof copolymer half-finished product in a mold. The copolymer is synthesized by block copolymerization of acrylonitrile and acrylic acids with simultaneous introduction into the monomer mixture of all components for foaming and adjusting the properties of the future foam material $[12,13]$.

The world leader in the supply of a wide range of rigid sheet polyimide foams for structural and radiotechnical purposes is Evonik (Germany), which has developed various brands of this material under the general name Rohacell.

At present, the structural profiles with filler, made of foam material Rohacell, are successfully used in the designs of aircraft.

An example is the stringer-profiles, filled with foam polyimide material, used for the construction of rear pressure bulkhead of Airbus A340 and A 340-360. The key to the successful introduction of apolyimide foam-filled trapezoidal stringer construction was the ease of mechanical machining and the final 
thermoforming of Rohacell. Filled with polyimide foam, trapezoidal profile contributes to the increase in the stability of thin-walled structures, made ofcarbon fiber reinforced plastic and their resistance to longitudinal bending and axial load. The appliance of Rohacell as a stiffener allows to use one or two layers of CFRP on the walls of the structure and thus to obtain weight gain [14].

In the helicopter industry, high-tech blades with a Rohacell foam core were developed. A high level of mechanical properties of the foam improves the resistance to longitudinal bending of the thinnest Ushaped spars, used for the construction of blades. Due to passive behavior, which is not typical for any other foam, polyimide foam materials withstand the high dynamic loads, to which the main rotor blade is subjected during its operation [14].

\section{Methods}

The microstructure analysis was carried out with the microscope Altami MET 3, using Altami Studio software.

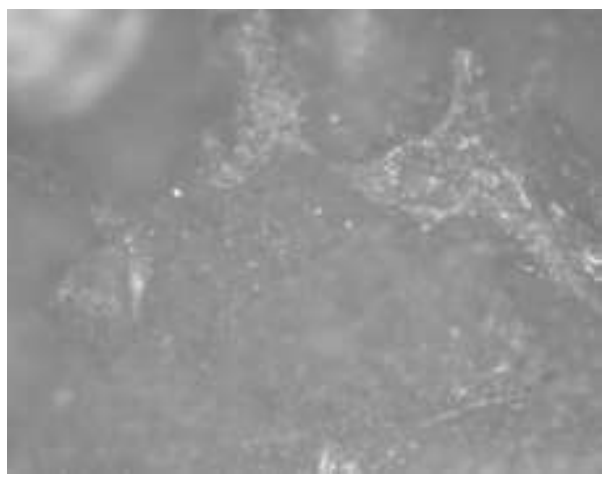

Sample 1
Differential scanning calorimetry (DSC analysis) was established using a differential scanning calorimeter of heat flow "Netzsch DSK 204 F1 Phoenix". The DSC analysis was carried out in a dynamic heating/cooling regime at a rate of $10^{\circ} \mathrm{C} / \mathrm{min}$ in an argon flow at a rate of $50 \mathrm{~cm}^{3} / \mathrm{min}$.

The thermal stability of samples was investigated using the thermogravimetric analyzer "Netzsch TG $209 \mathrm{~F} 1$ Iris". Heating to $550^{\circ} \mathrm{C}$ was carried out at a rate of $10 \mathrm{~K} / \mathrm{min}$ under the conditions of constant purging by argon.

The functional composition and the structure of samples were determined using FT-IR spectroscopy "Perkin Elmer Spectrum 100" with ATR crystal $\mathrm{ZnSe}$.

\section{Results and Discussion}

It is known, that Rohacell foam materials are characterized by technological parameters of foaming, molding temperature, foam structure, and mechanical properties.

The structure of the rigid polyimide foams under study (Sample 1 and 2) is shown in Figure 1.

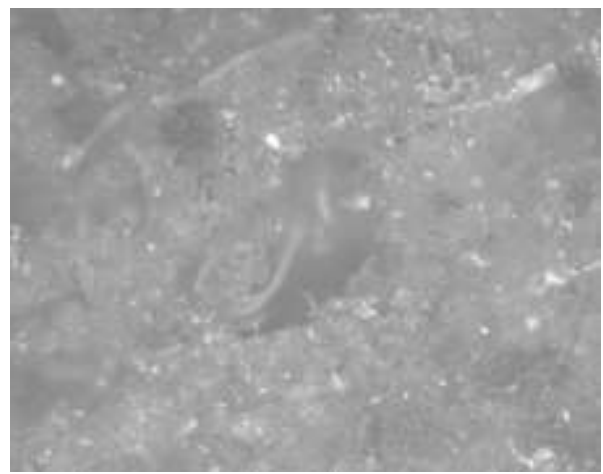

Sample 2

Figure 1. Photomicrographs of Cells of Foam Samples of Rohacell Brand (x 200)

Sample 1 is characterized by the presence of larger cells, than sample 2. Consequently, in relation to each other, the sample 1 of rigid polyimide foam is coarsely cellular and the sample 2 is finely porous.

Thermal analysis provides an opportunity to obtain information about the mechanism of materials destruction, chemical changes in the substanceand other processes. Applying this method, using the obtained data, it is possible to analyze the thermal decomposition of the foam material.

Thermogravimetric (TG) analysis shows important information about the thermal stability of a substance and its behavior upon the application of heat.
In the process of thermal analysis, the changes of the following parameters are defined:

- mass of the test sample in dependence to its heating temperature;

- the rate of the sample mass loss in dependence to its heating temperature.

Based on the analysis of these parameters, it is possible to obtain sufficiently complete information on the kinetics of destruction of the investigated foam material [15].

Initial information about the thermal stability of the material was obtained by analyzing the stages of foams destruction, according to the TG curve (Table 1, Figure 2). 


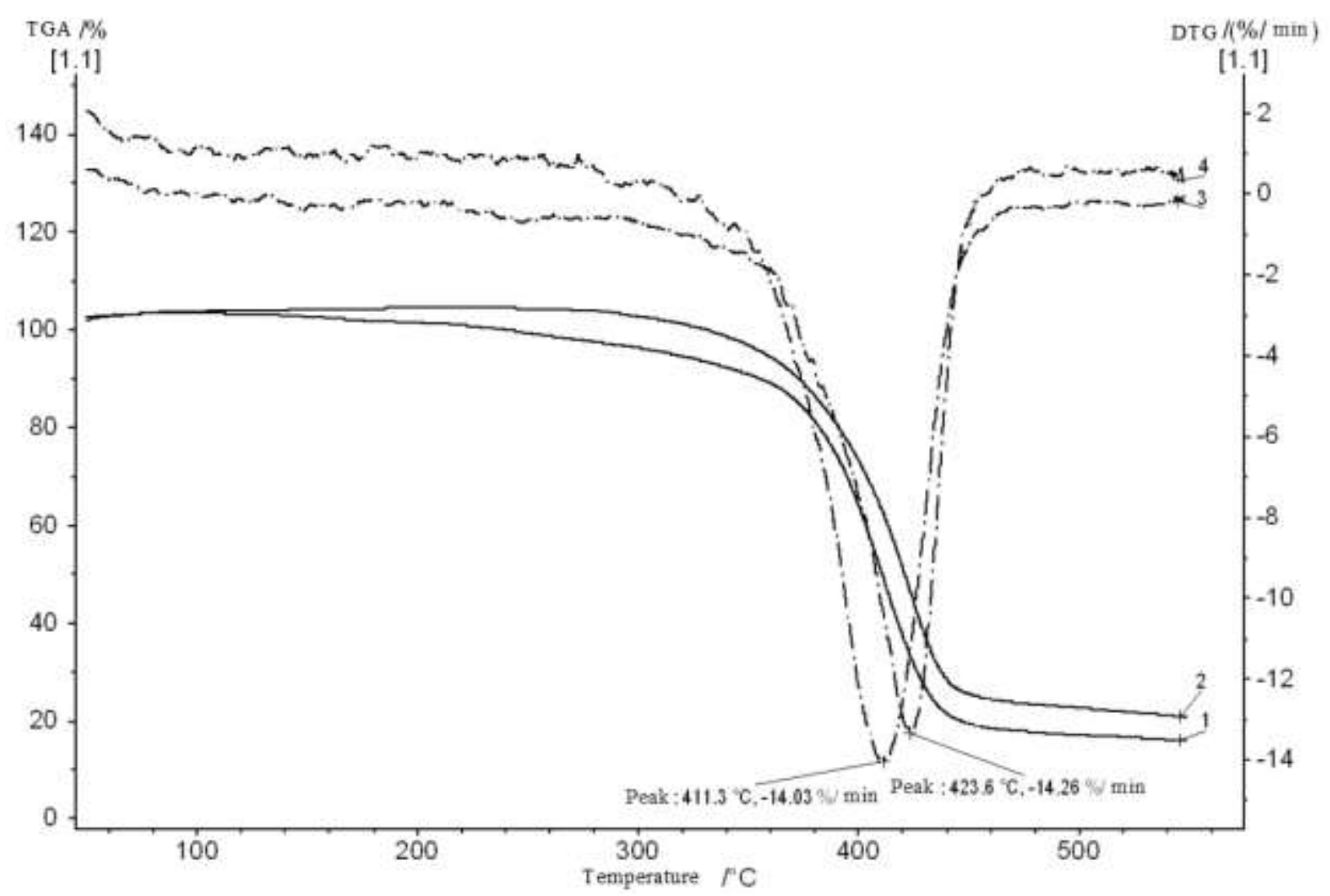

Figure 2.Thermogravimetric Analysis of Rigid Polyimide Foams sSample 1 (curve TGA - 1, curve DTG - 3) and Sample 2 (curve TGA - 2, curve DTG - 4)

From the thermograms of the test samples of rigid polyimide foams (Figure 2), the onset temperature of decomposition $\left(T_{\mathrm{o}}\right)$, the loss of mass at the time of reaching the temperature of maximum decomposition rate $\left(T_{\max }\right)$, the remaining material at $550^{\circ} \mathrm{C}$ (Table 1$)$ were determined. As can be seen from Table 1 and Figure 2, theloss ofmass of all samples has undergone several stages of different intensity.

Table 1. Results of Thermal Studies of Samples of Rigid Polyimide Foams

\begin{tabular}{|l|l|l|}
\hline Parameter & Sample 1 & Sample 2 \\
\hline Glass Transition Temperature, ${ }^{\circ} \mathrm{C}$ & 109,2 & 93,5 \\
\hline Loss of mass up to $300{ }^{\circ} \mathrm{C}, \%$ mass. & 0,9 & 7,0 \\
\hline$T_{\text {o }}$ destruction, ${ }^{\circ} \mathrm{C}$ & 379,2 & 376,7 \\
\hline$T_{\max }$ of destruction, ${ }^{\circ} \mathrm{C}$ & 423,6 & 411,3 \\
\hline Loss of mass at $T_{\max }$ of destruction, \% mass. & 38,2 & 38,5 \\
\hline Remaining mass at $550^{\circ} \mathrm{C}, \%$ mass. & 22,7 & 16,0 \\
\hline
\end{tabular}

Decomposition of the samples under study is threestep. For the samples of rigid polyimide foams, the following stages of thermal destruction process were defined:

$-30-300^{\circ} \mathrm{C}$ - decomposition of polyimide into the primary products and removal of volatile components;

$-310-550^{\circ} \mathrm{C}-$ activation of thermo-oxidative processes and decomposition, accompanied by significant heat release;

$\rightarrow 550^{\circ} \mathrm{C}$-termination of the material destruction.

Analyzing the TG data and the results of their processing (Table 1, Fig. 2), it can be noted, that the first low-temperature stage for the samples under investigation is characterized by a range of $30-300^{\circ} \mathrm{C}$, while sample 2 loses about $7 \%$ of mass, and sample 1 - only $0,9 \%$ of mass.

The second stage of the process is characterized by an intense destruction in the temperature range of $310-550^{\circ} \mathrm{C}$, and significant loss of mass for all samples $(38.2-38.5 \%)$. This indicates the active processes of thermal destruction and decomposition. Moreover, $T_{\mathrm{o}}$ and $T_{\max }$ of decomposition of the sample 2 are lower than the temperaturesof the sample 1 . This is explained by the acceleration of reactions by the decomposition products, formed at the first stage. Thus, $T_{\mathrm{o}}$ of decomposition of the sample 2 is lower by 
$2.5^{\circ} \mathrm{C}$, and $T_{\max }$ of decomposition is lower by $12.3^{\circ} \mathrm{C}$, than the decomposition temperatures of the sample 1 . It is known, that the glass transition temperature of copolymers of acrylonitrile and methacrylic acids is characterized by a range of $100-110^{\circ} \mathrm{C}$. The glass transition temperature of the test sample 1 is $109.2^{\circ} \mathrm{C}$, and the sample 2 is $93.5^{\circ} \mathrm{C}$ (Table 1). The low glass transition temperature of sample 2 is due to the presence of residual monomers, which act as plasticizers, reducing the glass transition temperature. The investigations, conducted with using FT-IR spectroscopy, as well as the emissions of volatile components at the first stage of thermal destruction process (up to $7 \%$ of mass) of sample 2 (Table 1) confirm this fact.

The composition of foams was determined by the method of "Fourier transform spectroscopy". Peaks, typical for copolymers of acrylonitrile and acrylic acids are present on the IR-spectra (Figure 3) of samples 1 and 2: stretching vibrations of $\mathrm{CH}_{2}$ of the main chain $\left(1453 \mathrm{~cm}^{-1}\right), \mathrm{C}-\mathrm{O}$ and $\mathrm{C}=\mathrm{O}$ groups of aliphatic esters of acrylic acids in the range of 1160 $\mathrm{cm}^{-1}$ and $1736-1715 \mathrm{~cm}^{-1}$, respectively, $C N$ groups of acrylonitrile $\left(2238 \mathrm{~cm}^{-1}\right)$.

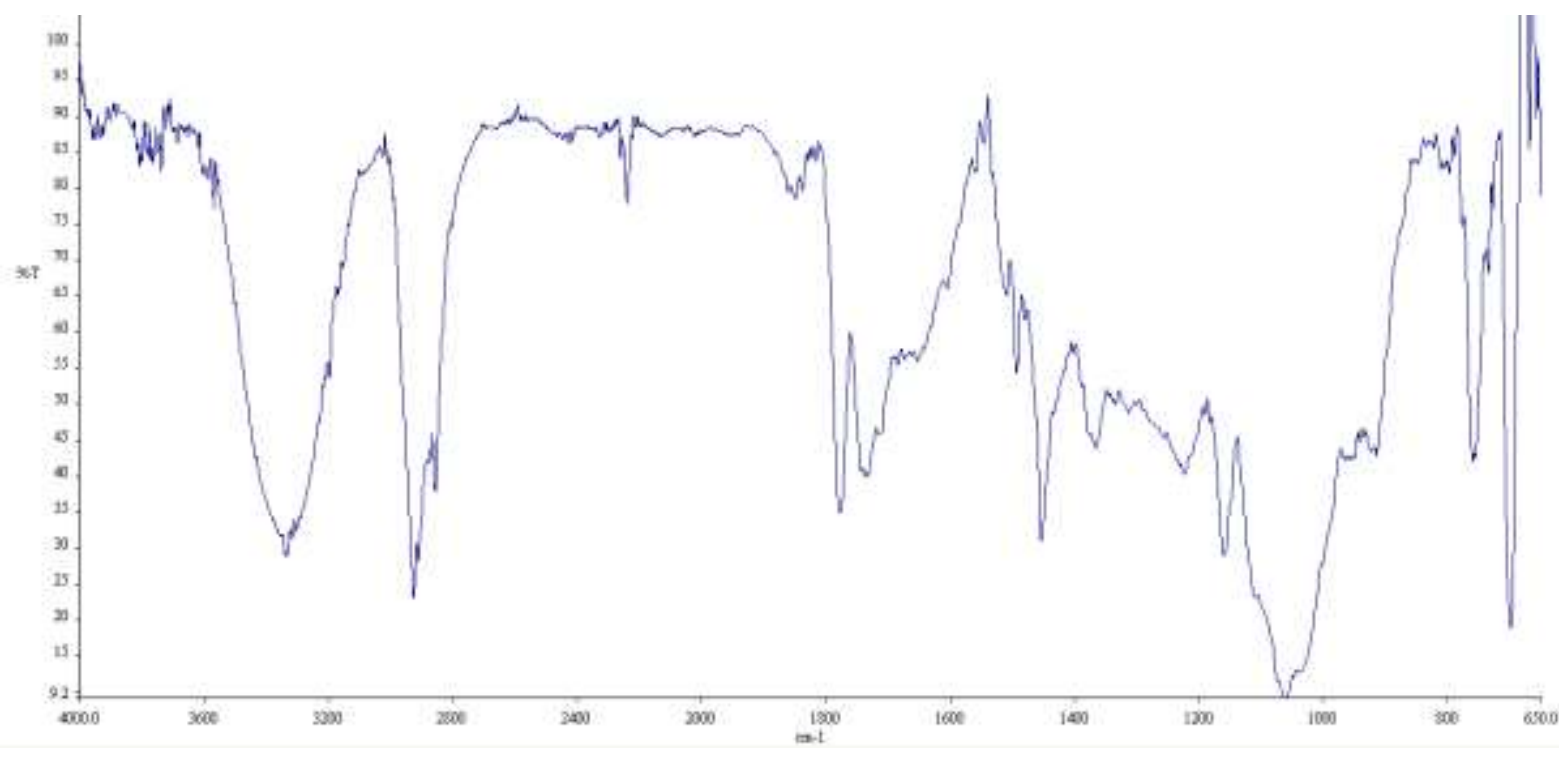

Figure 3. IR Spectrum of the Test Sample 1

Thus, the thermal decomposition of rigid polyimide foam samples has undergone three stages of different intensity.

\section{Conclusion}

Conducted studies showed, that the process of thermal destruction of rigid polyimide foams had undergone three stages. At the first stage, there were the destruction of rigid segment, with formation of initial components and the emission of volatile elements. The sample can contain them up to $7 \%$ of mass. This leads to a decrease in the onset temperature of decomposition and the temperature of the maximum decomposition rate. At the second and the third stages, there werethe activation of thermooxidative processes and decomposition, accompanied by a significant heat release. This fact is explained by the acceleration of thermooxidative reactions by the products, formed at the first stage of thermal decomposition.

\section{Acknowledgements}

The work was carried out jointly with the specialists of the "Central Laboratory of Non-Metallic Materials", Public Joint Stock Company "KAMAZ".

\section{References}

[1]Siriruk A., Jack Weitsman Y., Penumadu D. Polymeric foams and sandwich composites: material properties, environmental effects, and shear-lag modeling // composites science and technology, 2009. - Vol.69. №6. - Pp. 814-820.

[2]Terentyeva N.N. Laboratory course on the discipline of polyurethane chemistry / N.N. Terentyeva, V.A. Danilov, M.V. Kuzmin, S.M. Verkhunov // Textbook. - Moscow: Chuvash state university n. a. I.N. Ulyanov, 2007. - 97 p.

[3]Neng N.R., Pinto M.L., Pires J., Nogueira J.M.F., Marcos P.M. Development, optimization and application of polyurethane foams as new polymeric phases for stir bar sorptive extraction // Journal of chromatography A., 2007 - Vol.1171. №2. - Pp. 8-14. [4]Kovalevskaya, I.V. Modification of polyurethane hermetics by dispersed inorganic fillers / I.V. Kovalevskaya, G.R. Khusainova, T.R.Safiullina, L.A. Zenitova // Bulletin of Kazan State Technological University. - 2010. - №1.- Pp.225-233.

[5]Kiyanenko E.A. Physical and mechanical properties of polyurethane coatings, filled with solid inorganic fillers / E.A. Kiyanenko, L.A.Zenitova // 
Bulletin of Kazan State Technological University. 2011. - №19. - Pp.92-96.

[6]Shafigullin, L.N., Bobrishev, A.A., Erofeev, V.T., Treshchev, A.A., Erofeev, V.T., Shafigullina, A.N. Development of the recommendations on selection of glass-fiber reinforced polyurethanes for vehicle parts. // International Journal of Applied Engineering Research, Volume 10, Issue 23, 2015. - Pp. 4375843762.

[7]Zharin D.E., Yurasov S.Y., Gumerov M.I., Shafigullin, L.N., Optimal machining of loosely filled polymer composites // Russian Engineering Research, 2010. - Vol. 29, №10 - Pp. 1007-1009.

[8]Gotlib, E.M., Galimov, E.R., Zenitova, L.A., et al., Poliuretany: sintez, svoistvaiprimenenie v mashinostroenii: uchebnoeposobie (Polyurethanes: Synthesis, Properties, and Use in Machine Engineering: Manual), Kazan: Kazan. Gos. Univ., 2016.

[9]Zharin D.E., Yurasov S.Y., Gumerov M.I., Shafigullin, L.N., Vibration-andnoise-absorbing polymer composites, used in manufacturing // Russian Engineering Research, 2010. Vol. 30, № 2 Pp. 194-196.

[10]Shafigullin L.N., YurasovS.Yu., Shayakhmetova G.R., Shafigullina A.N., Zharin E.D. SoundAbsorbing Polyurethane Foam for the Auto Industry (article) // Russian Engineering Research, 2017. Vol. 37, №4. - Pp. 38-40.

[11] Chamberlain G. The ins and outs of automotive materials // Design News, 1996. - Vol. 51, № 19. Pp. 95-97.

[12] Timoshenko N.V., Filatov S.N. Copolymerization of acrylonitrile and methacrylic acid in an aqueous medium. Advances of Chemistry and Chemical Technology.Issue №3 (119)/ Vol. 25/2011. Pp. 45-49.

[13] Timoshenko N.V., Kireev V.V., Filatov S.N., Terekhov I.V. The influence of copolymerization conditions of acrylic monomers on the composition and properties of copolymers. Advances of Chemistry and Chemical Technology.Vol. XXIV. 2010. № 2 (107). Pp. 90-94.

[14]BeyderE.Ya., Gureeva E.V., Petrova G.N. Foamed polyimides. All-Russian Institute of Aviation Materials / 2011-205894-1 www.viam.ru/public (Date of access: 30/05/2017).

[15]Beschastnykh A.N. Expert research of products of oxidative destruction of building materials and interior elements from polyurethane foams [Text]: A thesis for a Doctor's of Technical Sciences degree (05.26.03)/Beschastnykh Andrey Nikolaevich; St. Petersburg University. - St. Petersburg, 2002. - 121 p. 